\title{
A EDUCAÇÃO A DISTÂNCIA NA QUALIFICAÇÃO DE PROFISSIONAIS PARA O SISTEMA ÚNICO DE SAÚDE: METAESTUDO
}

\author{
DISTANCE EDUCATION IN THE TRAINING OF PROFESSIONALS FOR THE UNIFIED HEALTH SYSTEM: \\ META-STUDY
}

LA EDUCACIÓN A DISTANCIA EN LA CALIFICACIÓN DE PROFESIONALES PARA EL SISTEMA ÚNICO DE SALUD: METAESTUDIO

\author{
Francisca Maria de Almeida Vargas ${ }^{1}$ \\ Mônica Cristina Nunes da Trindade ${ }^{2}$ \\ Gisele Damian Antonio Gouveia ${ }^{3}$ \\ Mareni Rocha Farias ${ }^{4}$
}

Resumo Este estudo objetivou caracterizar concepções teórico-pedagógicas em educação a distância na formação/qualificação de trabalhadores do Sistema Único de Saúde e identificar cursos em educação a distância, amparados neste contexto. A busca sistematizada envolveu estudos qualitativos, utilizando os termos: 'educação a distância' e 'saúde'. Selecionaram-se 21 estudos para compor o metaestudo, que consistiu de três etapas: metateoria, metamétodos e metanálise. Na metateoria, identificaram-se quatro categorias: construtivismo; pedagogia de Paulo Freire; educação permanente em saúde; e concepções próprias da educação a distância. Na etapa metamétodos, 11 estudos eram relatos de experiência; dois, estudos de caso; três envolveram análise de conteúdo; um envolvia pesquisa-ação; e outro, análise do discurso. Na metanálise, identificaram-se resultados que marcaram: formação de comunidades de aprendizagem; fortalecimento dos espaços de gestão; e formação de redes para projetos em educação permanente. As discussões enfatizaram: fortalecimento do Sistema Único de Saúde; protagonismo dos sujeitos; e formação de redes de cuidados. Constata-se que os estudos se restringiram mais aos aspectos conceituais e teóricos do que aos metodológicos. Ficaram evidentes conceitos amparados no construtivismo, na educação permanente em saúde e em referencial teórico próprio da educação a distância. Nos estudos, a educação a distância foi considerada indispensável para formação/qualificação de profissionais no Sistema Único de Saúde.

Palavras-chave educação a distância; Sistema Único de Saúde; trabalhadores.
Abstract This study aimed to characterize theoretical and pedagogical concepts in distance education in the training/qualification of employees of the Unified Health System and to identify courses in distance education, supported in this context. The systematic search involved qualitative studies using the terms 'distance education' and 'health.' In all, 21 studies were selected to compose the meta-study, which consisted of three stages: Metatheory, metamethods, and meta-analysis. Four categories were identified in the metatheory: Constructivism; the pedagogy of Paulo Freire; continuing education in health; conceptions belonging specifically to distance education. The metamethods step found 11 experience reports; two case studies; three involved content analysis; one involved action research; and the another, discourse analysis. Marking results were found in the meta-analysis: Formation of learning communities; strengthening of management spaces; formation of network for projects in continuing education. The discussions emphasized strengthening the Unified Health System, the protagonism of the subjects, and the formation of care networks. It was noted that the study focuses on the more conceptual and theoretical aspects than on the methodological ones. Concepts supported in Constructivism, in continuing education in health, and in a theoretical framework of distance education itself were evident. In the studies, distance education was considered essential for training/qualifying professionals in the Unified Health System.

Keywords distance education; Unified Health System; workers. 


\section{Introdução}

Nos últimos anos, mediante o desenvolvimento das tecnologias de informação e comunicação (TICs), sobretudo as digitais, houve uma expansão na oferta de propostas em educação a distância (EAD) (Garcia e Baptista, 2007). No Brasil, desde a promulgação da Lei de Diretrizes e Bases da Educação Nacional (LDB, n. 9.394, de 1996), esse modo de fazer educação passou a ser uma questão de cidadania e dever do Estado (Brasil, 1996). O decreto n. 5.622/2005, que regulamenta o artigo 80 da lei n. 9.394/96, a conceitua como uma modalidade cuja mediação didático-pedagógica ocorre provida de TICs, com aprendizes e docentes desenvolvendo suas atividades em tempos e lugares diversificados (Brasil, 2005).

O Sistema Único de Saúde (SUS) tem responsabilidade direta na qualificação/formação de seus profissionais, conforme evidenciado desde a Constituição Federal de 1988 e a Política Nacional de Educação Permanente em Saúde (PNEPS) (Brasil, 1998, 2007, 2009). Nesse contexto, a EAD tem sido utilizada na formação/qualificação de profissionais da área da saúde no país. Tal modo de fazer educação tem sido uma estratégia para qualificação dos profissionais, especialmente aqueles oriundos de uma graduação marcada pela relação verticalizada professor-aluno, apoiada no positivismo e no olhar reducionista do modelo biomédico.

A EAD, quando respaldada em propostas pedagógicas que favoreçam ambientes cooperativos e construtivistas de aprendizagem, pode oportunizar a horizontalização entre professor e aluno, assim como a formação de redes colaborativas de aprendizagem e interação. Acrescente-se a isso a possibilidade de se alcançarem grandes demandas de profissionais que necessitam de qualificação (Parente, 2004; Castells, 1999; Paim e Guimarães, 2009; Rangel-S et al., 2012). Portanto, tem-se investido em concepções teórico-pedagógicas que reconheçam o educando como sujeito ativo no seu processo de aprendizagem, como a lógica norteadora dos princípios da aprendizagem significativa; da metodologia da problematização; das pedagogias histórico-construtivistas e do referencial teórico da educação permanente em saúde (EPS) (Paim e Guimarães, 2009; Rangel-S et al., 2012; Paim, Alves e Ramos, 2009).

Nos últimos anos, houve fortalecimento dos aspectos teóricos relacionados à EAD; contudo, constatam-se fragilidades e variedades de concepções e práticas. Conforme afirma Torres (2005), torna-se relevante o estudo de componentes essenciais para a construção de bases teóricas. Nesse contexto, considera-se importante identificar as abordagens teórico-pedagógicas utilizadas na EAD no campo da saúde, especificando os cursos e objetos de estudo nessas publicações, assim como seus resultados e discussões.

É necessário sistematizar tais componentes e produzir uma síntese. O metaestudo pode ser uma alternativa, pois parte das publicações sobre EAD 
na área da saúde, no Brasil, foi realizada na perspectiva da pesquisa qualitativa, utilizando-se, sobretudo, as metodologias de estudo de caso e relato de experiência. O metaestudo produz evidências qualitativas que permitem realizar uma leitura crítica das interpretações nos estudos qualitativos, norteando-se por parâmetros metodológicos rigorosos, sistemáticos e objetivos (Paterson et al., 2001).

Este artigo teve como objetivo caracterizar as concepções teórico-pedagógicas em EAD na formação/qualificação de trabalhadores do SUS e identificar cursos dessa modalidade como objetos de estudo nessas publicações, mostrando resultados e discussões dos autores.

\section{O processo de revisão, seleção e análise dos estudos com abordagem qualitativa}

Realizou-se uma revisão de literatura reconhecida como metaestudo (Paterson et al., 2001), com a busca direcionada pelas perguntas: Quais as características teórico-pedagógicas em EAD na área da saúde no Brasil no período de 1992 a 2014? Quais cursos em EAD são evidenciados nos estudos?

As etapas do metaestudo incluíram: criação do grupo de pesquisadores, desenvolvimento da questão do estudo; critérios de inclusão e exclusão; metanálise de dados, metamétodos, metateoria e metassíntese (Paterson et al., 2001; Castellanos et al., 2011; Spadacio et al., 2010; Antonio, Tesser e Moretti-Pires, 2013).

As bases de dados SciELO, Lilacs e Pubmed foram utilizadas para localização dos estudos. A seleção de tais estudos foi realizada após leitura dos títulos e resumos. Na dúvida, leu-se na íntegra.

\section{Procedimentos de busca}

Os descritores 'educação a distância' and 'saúde' foram utilizados nas bases de dados SciELO e Lilacs, e 'distance education' and 'health', na base de dados Pubmed. Localizaram-se 51 artigos na base de dados SciELO, 82 na Lilacs e 118 na Pubmed.

\section{Critérios de elegibilidade (inclusão e exclusão)}

Incluíram-se estudos originais referentes a pesquisas qualitativas produzidas no Brasil com dados primários sobre EAD para formação/qualificação de profissionais da saúde, na forma de estudos de caso; relatos de experiências sobre cursos a distância com reflexão teórica; descrição de cursos ou 
avaliação de materiais para EAD; estudos teóricos/reflexivos sobre EAD; e desenvolvimento/avaliação de ambientes virtuais de aprendizagem. Para este estudo, foram considerados artigos qualitativos que versassem sobre EAD no contexto da utilização das tecnologias digitais e ambientes virtuais de aprendizagem. Consideraram-se aptos para inclusão os estudos em que a EAD estava voltada tanto para profissionais de saúde inseridos no serviço quanto para a formação de docentes/tutores.

$\mathrm{O}$ processo de análise resultou em 21 estudos, conforme descrito no Quadro 1.

\section{Quadro 1}

\begin{tabular}{|c|c|}
\hline \multicolumn{2}{|l|}{ Síntese do processo de obtenção dos artigos selecionados para o metaestudo } \\
\hline Busca na base de dados & \\
\hline SCIELO & $N=51$ \\
\hline Lilacs & $N=82$ \\
\hline Pubmed & $N=118$ \\
\hline Reunião das três bases de dados - exclusão de duplicidades & $\mathrm{N}=249$ \\
\hline Análise dos títulos e resumos/exclusão & \\
\hline Artigos cujo cenário não é do Brasil & $N=153$ \\
\hline Artigos cujo cenário é no Brasil, mas com abordagem quantitativa & $N=9$ \\
\hline Artigos com cenário no Brasil, mas não localizados & $N=1$ \\
\hline Artigos de revisão de literatura & $\mathrm{N}=12$ \\
\hline Artigos de debates & $N=4$ \\
\hline Desenvolvimento de páginas educacionais & $N=5$ \\
\hline EAD por materiais instrucionais - livros & $N=4$ \\
\hline EAD teleconferência saúde/videoconferência/telenfermagem/teleamamentação & $N=5$ \\
\hline EAD por tecnologia que envolve realidade virtual & $N=1$ \\
\hline Estudos de EAD voltados para graduação & $N=7$ \\
\hline Não tratavam diretamente sobre EAD & $\mathrm{N}=3$ \\
\hline Análise e discussão de software de leitores de tela & $N=1$ \\
\hline Artigos elegíveis & $N=21$ \\
\hline
\end{tabular}

Fonte: As autoras. 


\section{Análise dos dados}

Para a tabulação de dados, utilizou-se o software Microsoft Excel 2010. Os itens tabulados foram: nome dos autores, título do artigo, revista, ano de publicação, instituições envolvidas, país onde foi desenvolvido o estudo, objetivo, população de referência, técnica de amostragem, técnica de coleta, fundamentação teórica, método, principais resultados, análises ou discussões e conclusão.

Os estudos selecionados foram analisados com base nos pressupostos teóricos (metateoria), abordagem metodológica (metamétodo) e resultados dos estudos (metanálise dos dados). Por intermédio dessas sínteses parciais, elaboraram-se uma síntese final e um mapa conceitual à luz do referencial teórico do marco da Reforma Sanitária, do construtivismo, da EPS e da teoria da complexidade de Edgar Morin (Morin, 2005, 2011).

\section{Caracterização das publicações e etapas do metaestudo}

Verificou-se uma concentração das publicações entre os anos de 2003 e 2012, distribuídos em periódicos na área de saúde coletiva/saúde pública, com participação de diferentes pesquisadores. O Quadro 2 relaciona as instituições dos autores; a teorização dos estudos por cursos de formação/qualificação ou projetos em EAD; os parceiros envolvidos nos cursos/projetos; e o público-alvo.

Quadro 2

\begin{tabular}{|c|c|c|c|c|c|c|c|c|c|}
\hline \multicolumn{4}{|c|}{ Caracteriza ção do estudo } & \multicolumn{5}{|c|}{ Caracterização do método e análise do estudo } & \multirow{2}{*}{$\begin{array}{l}\text { Total } \\
\text { por } \\
\text { ano }\end{array}$} \\
\hline $1^{\circ}$ autor & Ano & Local & Curso ou projeto & A quem se destina & Amostra & $\begin{array}{c}\text { Técnica coleta } \\
\text { de dados }\end{array}$ & \begin{tabular}{|c|} 
Tipo de estudo/ \\
técnica de análise
\end{tabular} & $\begin{array}{c}\text { Aspectos } \\
\text { éticos }\end{array}$ & \\
\hline Oliveira & 2013 & $\begin{array}{l}\text { Maranhão: } \\
\text { UFMA }\end{array}$ & $\begin{array}{l}\text { Curso de Especialização em } \\
\text { Saúde da Família } \\
\text { e Saúde Materno Infantil }\end{array}$ & $\begin{array}{c}\text { Profissionais de saúde } \\
\text { do SUS }\end{array}$ & NA & NA & $\begin{array}{c}\text { Relato de } \\
\text { experiência }\end{array}$ & NA & 1 \\
\hline Rangel-S & 2012 & Bahia:UFBA & $\begin{array}{l}\text { Curso de Especialização em } \\
\text { Saúde Coletiva: concentração } \\
\text { em gestão municipal }\end{array}$ & $\begin{array}{l}\text { Profissionais da saúde: } \\
\text { gestores municipais; } \\
\text { membros da equipe gestora; } \\
\text { técnicos em gestão }\end{array}$ & NA & Misto & $\begin{array}{c}\text { Relato de } \\
\text { experiência }\end{array}$ & $\mathrm{N}$ & 2 \\
\hline
\end{tabular}


Continuação - Quadro 2

Relação de estudos caracterizados quanto ao ano de publicação, local de realização, nome do curso ou projeto, público-alvo, amostragem, técnica de coleta de dados e análise

\begin{tabular}{|c|c|c|c|c|c|c|c|c|c|}
\hline \multicolumn{4}{|c|}{ Caracterizaçăo do estudo } & \multicolumn{5}{|c|}{ Caracterização do método e análise do estudo } & \multirow{2}{*}{$\begin{array}{l}\text { Total } \\
\text { por } \\
\text { ano }\end{array}$} \\
\hline $1^{\circ}$ autor & Ano & Local & Curso ou projeto & A quem se destina & Amostra & $\begin{array}{c}\text { Técnica coleta } \\
\text { de dados }\end{array}$ & $\begin{array}{l}\text { Tipo de estudo/ } \\
\text { técnica de análise }\end{array}$ & $\begin{array}{c}\text { Aspectos } \\
\text { éticos }\end{array}$ & \\
\hline Brutscher & 2012 & $\begin{array}{c}\text { Paraíba: } \\
\text { UFPB; } \\
\text { Ensp/Fiocruz }\end{array}$ & $\begin{array}{c}\text { Curso Nacional de Qualificação } \\
\text { de Gestores do SUS na Paraíba; } \\
\text { Curso de Especialização em } \\
\text { Sistemas e Serviços de Saúde }\end{array}$ & $\begin{array}{l}\text { Gestores e profissionais } \\
\text { do SUS }\end{array}$ & NA & NA & Teórico reflexivo & NA & 2 \\
\hline Laguardia & 2010 & $\begin{array}{c}\text { Rio de } \\
\text { Janeiro: } \\
\text { Ensp/Fiocruz }\end{array}$ & NA & $\begin{array}{c}\text { Trabalhadores e } \\
\text { profissionais das secretarias } \\
\text { municipais de Saúde }\end{array}$ & NR & Entrevista & Conteúdo & $S$ & 2 \\
\hline Nunes & 2010 & $\begin{array}{l}\text { Rio Grande } \\
\text { do Sul:PUCRS }\end{array}$ & NA & NA & NR & Mista & Estudo de caso & NR & 2 \\
\hline Paulon & 2009 & $\begin{array}{l}\text { Rio Grande } \\
\text { do Sul: } \\
\text { UFRGS; } \\
\text { Ensp/Fiocruz }\end{array}$ & $\begin{array}{l}\text { Curso de Pós-Graduação em } \\
\text { Humanização da Gestão e } \\
\text { Atenção ao SUS }\end{array}$ & $\begin{array}{c}\text { Apoiadores institucionais da } \\
\text { humanização da atenção e } \\
\text { gestão do SUS }\end{array}$ & NR & Entrevista & Conteúdo & $S$ & 4 \\
\hline Alves & 2009 & $\begin{array}{c}\text { Bahia: Escola } \\
\text { de Formação } \\
\text { Técnica em } \\
\text { Saúde } \\
\end{array}$ & $\begin{array}{c}\text { Experiência de estruturação do } \\
\text { Sistema de EAD para formação } \\
\text { de formadores do EAD/SUS BA: } \\
\text { Projeto de incorporação do } \\
\text { ensino a distância na educação } \\
\text { permanente para } \\
\text { trabalhadores do SUS }\end{array}$ & $\begin{array}{l}\text { Formação de profissionais } \\
\text { da Escola Estadual de Saúde }\end{array}$ & NR & Mista & Estudo de caso & NR & 4 \\
\hline $\begin{array}{l}\text { Paim e } \\
\text { Guimarães }\end{array}$ & 2009 & $\begin{array}{l}\text { Bahia: Escola } \\
\text { Estadual de } \\
\text { Saúde } \\
\text { Pública }\end{array}$ & $\begin{array}{c}\text { Curso de Formação de } \\
\text { Professores-mediadores e } \\
\text { Autores para o projeto } \\
\text { EAD/SUS BA no contexto da } \\
\text { Educação Permanente no SUS }\end{array}$ & $\begin{array}{l}\text { Gestores e trabalhadores da } \\
\text { saúde }\end{array}$ & NA & NA & $\begin{array}{c}\text { Relato de } \\
\text { experiência }\end{array}$ & $\mathrm{N}$ & 4 \\
\hline $\begin{array}{l}\text { Paim, Alves e } \\
\text { Ramos }\end{array}$ & 2009 & $\begin{array}{l}\text { Bahia: Escola } \\
\text { Estadual de } \\
\text { Saúde } \\
\text { Pública }\end{array}$ & $\begin{array}{l}\text { Curso de Especialização em } \\
\text { Saúde da Família da Bahia }\end{array}$ & $\begin{array}{c}159 \text { gestores da atenção } \\
\text { básica }\end{array}$ & NA & NA & $\begin{array}{c}\text { Relato de } \\
\text { experiência }\end{array}$ & NA & 4 \\
\hline
\end{tabular}


Relação de estudos caracterizados quanto ao ano de publicação, local de realização, nome do curso ou projeto, público-alvo, amostragem, técnica de coleta de dados e análise

\begin{tabular}{|c|c|c|c|c|c|c|c|c|c|}
\hline \multicolumn{4}{|c|}{ Caracterização do estudo } & \multicolumn{5}{|c|}{ Caracterização do método e análise do estudo } & \multirow{2}{*}{$\begin{array}{l}\text { Tota } \\
\text { por } \\
\text { ano }\end{array}$} \\
\hline $1^{\circ}$ autor & Ano & Local & Curso ou projeto & A quem se destina & Amostra & $\begin{array}{c}\text { Técnica coleta } \\
\text { de dados }\end{array}$ & $\begin{array}{l}\text { Tipo de estudo/ } \\
\text { técnica de análise }\end{array}$ & $\begin{array}{c}\text { Aspectos } \\
\text { éticos }\end{array}$ & \\
\hline Cândido & 2008 & $\begin{array}{l}\text { São Paulo: } \\
\text { USP }\end{array}$ & NA & $\begin{array}{l}\text { Enfermeiros que trabalham } \\
\text { nos serviços de atenção } \\
\text { básica em saúde e que estão } \\
\text { em contato com pacientes } \\
\text { em depressão }\end{array}$ & NA & NA & $\begin{array}{c}\text { Relato de } \\
\text { experiência }\end{array}$ & $\mathrm{N}$ & 1 \\
\hline Dubeux & 2007 & $\begin{array}{c}\text { Bahia: } \\
\text { Instituições } \\
\text { parceiras - } \\
\text { Ensp/Fiocruz; } \\
\text { Imip; } \\
\text { ICS/UFBA; } \\
\text { Universidade } \\
\text { de Montreal }\end{array}$ & $\begin{array}{c}\text { Curso Básico de Avaliação em } \\
\text { Saúde do Imip }\end{array}$ & $\begin{array}{l}\text { Profissionais situados nas } \\
\text { três instâncias do SUS }\end{array}$ & NA & NA & $\begin{array}{c}\text { Relato de } \\
\text { experiência }\end{array}$ & N & 3 \\
\hline Garcia & 2007 & $\begin{array}{l}\text { Bahia: } \\
\text { Instituições } \\
\text { parceiras - } \\
\text { UFBA; } \\
\text { Escola de } \\
\text { Formação } \\
\text { Técnica; } \\
\text { Escola } \\
\text { Estadual de } \\
\text { Saúde } \\
\text { Pública }\end{array}$ & $\begin{array}{c}\text { Projeto de Incorporação de } \\
\text { Novas Tecnologias de } \\
\text { Informação e Comunicação no } \\
\text { Processo de Educação } \\
\text { Permanente para as Equipes do } \\
\text { Programa de Saúde da Família } \\
\text { (PSF) do Estado da Bahia e } \\
\text { curso para formação de tutores }\end{array}$ & $\begin{array}{l}\text { Profissionais de saúde do } \\
\text { PSF, agentes comunitários } \\
\text { de saúde (ACSs) e futuros } \\
\text { tutores (curso de formação) }\end{array}$ & NA & NA & $\begin{array}{c}\text { Relato de } \\
\text { experiência }\end{array}$ & NA & 3 \\
\hline Maia & 2006 & $\begin{array}{c}\text { Minas Gerais: } \\
\text { UEMG }\end{array}$ & NA & NA & NR & Mista & Pesquisa ação & $\mathrm{N}$ & 3 \\
\hline Barbosa & 2006 & $\begin{array}{c}\text { Rio de } \\
\text { Janeiro: } \\
\text { Ensp/Fiocruz }\end{array}$ & $\begin{array}{c}\text { Formação Pedagógica a } \\
\text { Distância de Trabalhadores da } \\
\text { Área de Enfermagem (Profae) }\end{array}$ & $\begin{array}{c}\text { Trabalhadores da área de } \\
\text { enfermagem }\end{array}$ & NA & Misto & Conteúdo & $S$ & 1 \\
\hline
\end{tabular}


Continuação - Quadro 2

Relação de estudos caracterizados quanto ao ano de publicação, local de realização, nome do curso ou projeto, público-alvo, amostragem, técnica de coleta de dados e análise

\begin{tabular}{|c|c|c|c|c|c|c|c|c|c|}
\hline \multicolumn{4}{|c|}{ Caracterização do estudo } & \multicolumn{5}{|c|}{ Caracterizaçăo do método e análise do estudo } & \multirow{2}{*}{$\begin{array}{l}\text { Total } \\
\text { por } \\
\text { ano }\end{array}$} \\
\hline $1^{\circ}$ autor & Ano & Local & Curso ou projeto & A quem se destina & Amostra & $\begin{array}{c}\text { Técnica coleta } \\
\text { de dados }\end{array}$ & $\begin{array}{c}\text { Tipo de estudo/ } \\
\text { técnica de análise }\end{array}$ & $\begin{array}{c}\text { Aspectos } \\
\text { éticos }\end{array}$ & \\
\hline Torres & 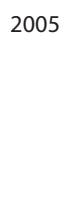 & $\begin{array}{c}\text { Rio de } \\
\text { Janeiro: } \\
\text { Ensp/Fiocruz; } \\
\text { Ministério da } \\
\text { Saúde }\end{array}$ & $\begin{array}{l}\text { Curso de Formação Pedagógica } \\
\text { em Educação Profissional na } \\
\text { Área da Saúde: Enfermagem }\end{array}$ & $\begin{array}{l}\text { Profissionais de saúde e } \\
\text { educadores }\end{array}$ & NA & NA & Teórico reflexivo & NA & 4 \\
\hline Carvalho & 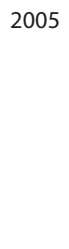 & $\begin{array}{l}\text { Rio Grande } \\
\text { do Sul: } \\
\text { Instituições } \\
\text { parceiras - } \\
\text { UFRGS; } \\
\text { PUCRS }\end{array}$ & Bioética & $\begin{array}{c}\text { Graduandos, pós- } \\
\text { graduandos e pesquisadores } \\
\text { e profissionais de saúde }\end{array}$ & NA & NA & $\begin{array}{c}\text { Relato de } \\
\text { experiência }\end{array}$ & NA & 4 \\
\hline Belloni & 2005 & $\begin{array}{l}\text { Santa } \\
\text { Catarina: } \\
\text { UFSC }\end{array}$ & NA & NA & NA & NA & Teórico reflexivo & NA & 4 \\
\hline Silva & 2005 & $\begin{array}{l}\text { Mato Grosso } \\
\text { do Sul: } \\
\text { Profae/ } \\
\text { Ministério } \\
\text { da Saúde }\end{array}$ & $\begin{array}{l}\text { Curso de Formação Pedagógica } \\
\text { em Educação Profissional na } \\
\text { Área da Saúde: Enfermagem }\end{array}$ & $\begin{array}{l}\text { Enfermeiros professores na } \\
\text { área de enfermagem }\end{array}$ & NR & Formulário & Discurso & $\mathrm{S}$ & 4 \\
\hline 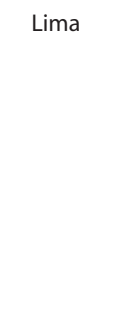 & 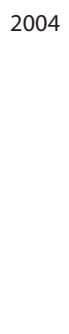 & $\begin{array}{l}\text { Espírito } \\
\text { Santo: } \\
\text { Instituições } \\
\text { parceiras - } \\
\text { Ufes; } \\
\text { Ministério } \\
\text { da Saúde; } \\
\text { Ensp/Fiocruz }\end{array}$ & $\begin{array}{l}\text { Curso de Especialização em } \\
\text { Formação Pedagógica em } \\
\text { Enfermagem }\end{array}$ & $\begin{array}{l}\text { Enfermeiros docentes da } \\
\text { educação profissional }\end{array}$ & NR & Questionário & Conteúdo & $\mathrm{S}$ & 1 \\
\hline Gondim & 2003 & $\begin{array}{l}\text { Rio Grande } \\
\text { do Norte: } \\
\text { Instituições } \\
\text { parceiras - } \\
\text { EPSJV/Fiocruz }\end{array}$ & $\begin{array}{c}\text { Programa de Formação de } \\
\text { Agentes Locais de Vigilância da } \\
\text { Saúde (Proformar) }\end{array}$ & $\begin{array}{l}\text { Agentes locais de vigilância } \\
\text { da saúde e guardas de } \\
\text { endemia da Funasa }\end{array}$ & NA & NA & $\begin{array}{c}\text { Relato de } \\
\text { experiência }\end{array}$ & NA & 1 \\
\hline
\end{tabular}


Continuação - Quadro 2

Relação de estudos caracterizados quanto ao ano de publicação, local de realização, nome do curso ou projeto, público-alvo, amostragem, técnica de coleta de dados e análise

\begin{tabular}{|c|c|c|c|c|c|c|c|c|c|}
\hline \multicolumn{4}{|c|}{ Caracterização do estudo } & \multicolumn{5}{|c|}{ Caracterização do método e análise do estudo } & \multirow{2}{*}{$\begin{array}{c}\text { Total } \\
\text { por } \\
\text { ano }\end{array}$} \\
\hline $1^{\circ}$ autor & Ano & Local & Curso ou projeto & A quem se destina & Amostra & $\begin{array}{c}\text { Técnica coleta } \\
\text { de dados }\end{array}$ & $\begin{array}{l}\text { Tipo de estudo/ } \\
\text { técnica de análise }\end{array}$ & $\begin{array}{c}\text { Aspectos } \\
\text { éticos }\end{array}$ & \\
\hline Struchiner & 2002 & $\begin{array}{c}\text { Rio de } \\
\text { Janeiro: UFRJ; } \\
\text { Opas }\end{array}$ & $\begin{array}{c}\text { Curso de Gestão } \\
\text { Descentralizada de Recursos } \\
\text { Humanos em Saúde }\end{array}$ & Profissionais de saúde & NA & NA & $\begin{array}{l}\text { Relato de } \\
\text { experiência }\end{array}$ & $\mathrm{N}$ & 1 \\
\hline
\end{tabular}

Fonte: As autoras.

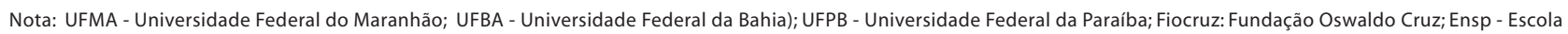

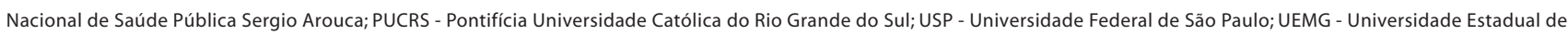

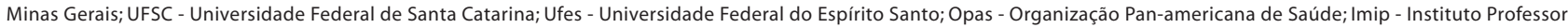

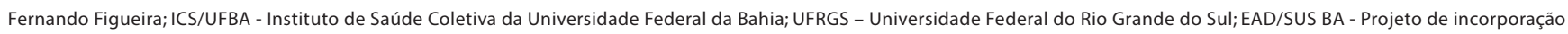

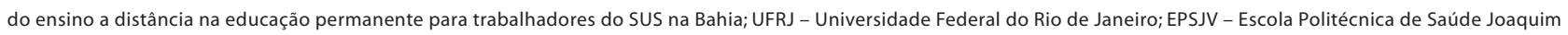
Venâncio; Funasa - Fundação Nacional de Saúde; NA - Não se aplica; NR - Não Referido; S - Sim; N - Não.

\section{Metateoria}

A análise das abordagens teórico-pedagógicas para EAD no campo da saúde, implícitas ou explícitas nos estudos, possibilitou o estabelecimento de quatro categorias: estudos em que ficaram marcados os referenciais teóricos clássicos nas perspectivas pedagógicas construtivistas; estudos que abordavam as concepções teórico-pedagógicas de Paulo Freire; estudos que ressaltavam a proposta pedagógica da educação permanente em saúde; e estudos que ficaram marcados com as concepções teóricas próprias da EAD.

\section{Referenciais teóricos clássicos nas perspectivas pedagógicas construtivistas}

Foram identificados quatro estudos (Struchiner, Roschke e Riciadi, 2002; Nunes, Franco e Silva, 2010; Maia et al., 2006; Laguardia, Casanova e Machado, 2010) que apresentaram os referenciais teóricos pedagógicos dos autores Lev Vigotsky, Jean Piaget e David Jonassen. Os problemas de pesquisa relacionados nesses estudos envolveram os temas: interação social no âmbito das tecnologias; aprendizagem construtivista e interação em ambientes virtuais; relação de cooperação; desenvolvimento cognitivo; aprendizagem tradicional e a necessidade de avançar para aprendizagem significativa e construtivista, que são importantes, para uma formação que intencione a descentralização e capacidade de negociação e a integralidade das ações de saúde. 
Dentre os conceitos assumidos para EAD, ressaltam-se os abordados pelos autores Belloni (2005) e Moore (1983). Outro referencial teórico apontado foi o de Edgar Morin (Morin, 2005, 2011) sobre a teoria da complexidade e a educação como um fenômeno complexo e vinculado à globalização.

\section{Referenciais teóricos abordando os ideais pedagógicos de Paulo Freire}

Fizeram parte desta categoria cinco estudos (Brutscher, Sampaio e Pereira, 2012; Barbosa e Rezende, 2006; Silva, Silva e Santos, 2005; Lima et al., 2004; Gondim e Monken, 2003). Os autores trabalharam o referencial teórico de Paulo Freire no âmbito das temáticas: autonomia do educando, ética e educação como uma prática social, e comunicação dialógica. Para a importância do diálogo, foi referenciada a ação comunicativa de Habermas (Habermas, 2001).

Outros temas foram identificados: horizontalização da aprendizagem; democratização da educação; compartilhamento do saber; construção de comunidades de aprendizagem; transformação dos sujeitos, tanto do educador quanto do aprendiz; relação com o outro e cidadania; necessidade de romper com a ideia prescritiva e de conceito de competência relacionada à lógica de mercado constante na LDB; e subjetivação da experiência do trabalhador. Também se identificaram nessa categoria as ideias dos autores Mehry e Onocko (1997), no que diz respeito à transformação dos sujeitos, tanto do educador quanto do aprendiz; relação com o outro, criação de vínculos; cumplicidade; e cuidado e cidadania.

Os referenciais teóricos adotados para EAD, nessa categoria, foram dos autores: Belloni (1999), Landin (1997), Moran (2005), Maggio (2001), Litwin (2001), Garcia e Aretio (2001) e Pretti (1998).

\section{Referencial teórico sobre a educação permanente em saúde}

Esta categoria foi composta de seis estudos (Garcia e Baptista, 2007; Paulon e Carneiro, 2009; Alves e Veloso, 2009; Paim, Alves e Ramos, 2009; Paim e Guimarães, 2009; Oliveira et al., 2013), que, de forma geral, se referiram à EAD e sua adequação aos pressupostos da EPS e aos princípios norteadores e diretrizes do SUS.

Os problemas de pesquisa relacionados abordaram os temas: formação protagonista para humanização; formação para gestão/cogestão; formação de redes; métodos educacionais que envolvam interdisciplinaridade nas equipes, interação, comunicação e informação no contexto da atenção básica; redes virtuais de educação em saúde; e gestão em EAD e propostas pedagógicas com maior alcance geográfico e maior número de trabalhadores. 
Os referenciais teóricos presentes entre os estudos para EAD foram as ideias de inteligência coletiva de Lévy; os conceitos de EAD de Belloni e Aretio e o conceito de EAD disponível no decreto n. 5.622/2005 (Lévy, 2000; Belloni, 1991; Aretio, 2001; Brasil, 2005).

Outro referencial teórico presente na categoria foi a comunicação em rede de Parente, que indica a necessidade de se provocarem deslocamentos muito mais subjetivos do que geográficos (Parente, 2004).

\section{Referencial da educação a distância}

Esta categoria foi composta por seis estudos (Rangel-S et al., 2012; Dubeux et al., 2007; Torres, 2005; Belloni, 2005; Carvalho, Muller e Ramos, 2005; Candido e Furegato, 2008). Os problemas de pesquisa relacionados abordaram os temas: formação/qualificação em avaliação de programas e serviços nas três instâncias gestoras; qualificação de gestores e profissionais na área da saúde pública e coletiva como uma forma de se alcançar a consciência cidadã; fortalecimento do SUS; descentralização e sua construção; importância de inovação técnica versus pedagógica; a EAD entendida como 'método' para ensinar e aprender; conhecimento atualizado do profissional de enfermagem em transtornos depressivos; e bioética como área de interação, discussão, reflexão e na qual o aluno deve ser o centro do processo ensino-aprendizagem.

Os referenciais teóricos presentes nos estudos foram a inteligência coletiva de Lévy (Lévy, 1996, 1999); a aprendizagem aberta de Belloni (Belloni, 2002); o conceito de EAD segundo Belloni e Moran (Belloni, 1999; Moran, 2003, 2005).

Outros referenciais teóricos presentes nos estudos foram: teoria da complexidade; interdisciplinaridade; sociedade complexa e a teoria da ordem e desordem de Edgar Morin (Morin, 1998, 2005); ação comunicativa segundo o pensamento de Habermas (Habermas, 2001); e sociedade em rede/redes colaborativas de Castells (Castells, 1999).

Não obstante as quatro categorias aqui configuradas, convém ressaltar que os estudos, de modo geral, citaram ou enfatizaram algum conceito para EAD.

Um dos conceitos citados para EAD foi o de Belloni (Belloni, 1999), no qual a EAD é considerada como novo modo de fazer educação mediada pelas TICs nas sociedades industriais modernas pós-fordistas. O conceito que Belloni atribui à EAD é: distanciamento geográfico combinado com encontros presenciais mediado por TICs síncronas ou assíncronas com orientação docente ou tutorial. Considera-se a aprendizagem aberta, flexível, em que o aluno exerce autonomia e gestão no seu processo de aprendizagem (Rangel-S et al., 2012; Laguardia, Casanova e Machado, 2010; Nunes, Franco e Silva, 2010; Torres, 2005; Belloni, 2005; Barbosa e Rezende, 2006; Brutscher, Sampaio 
e Pereira, 2012; Alves e Veloso, 2009; Paim, Alves e Ramos, 2009; Paim e Guimarães, 2009).

O conceito de EAD adotado por Moran (Moran, 2003, 2005) também foi mencionado. Para este autor, EAD é o processo de ensino-aprendizagem mediado por TICs, no qual estudantes estão separados física, espacial ou temporalmente. A EAD objetiva uma aprendizagem autônoma. A tutoria pode ser desempenhada de forma presencial, semipresencial ou a distância; os materiais precisam ser autoexplicativos e mais adequados (Dubeux et al., 2007; Candido e Furegato, 2008; Barbosa e Rezende, 2006; Brutscher, Sampaio e Pereira, 2012; Nunes, Franco e Silva, 2010).

Num terceiro grupo de artigos, os autores apontaram as ideias de Lévy (Lévy, 1996, 1999, 2000), em que a EAD é relacionada à cibercultura como um espaço de formação e novas relações com o saber-inteligência coletiva, no qual se considera o papel primordial da subjetividade. O docente é visto como 'um animador da inteligência coletiva', e o novo tipo de interação é no sentido 'todos-todos' nessa rede cooperativa de aprendizagem (Paim, Alves e Ramos, 2009; Paulon, 2009; Rangel-S et al., 2012; Maia et al., 2006).

\section{Metamétodo}

Nessa etapa, analisou-se a abordagem metodológica dos estudos, com destaque para a técnica de amostragem, coleta e análise de dados e aspectos éticos da pesquisa.

A abordagem metodológica utilizada pelas pesquisas foi diversa. Dos estudos analisados no Quadro 2, destacaram-se relatos de experiências, estudos de caso e teórico-reflexivos, pesquisa qualitativa, pesquisa-ação. Dentre os estudos que declararam a técnica utilizada de análise dos dados, foram mencionadas a análise de conteúdo e a análise do discurso.

\section{Metanálise}

Nesta seção, procurou-se sintetizar os principais resultados produzidos pelos estudos e discussões realizados pelos autores.

De modo geral os estudos evidenciaram que a EAD, quando conduzida nas perspectivas pedagógicas construtivistas, favorece a interação/cooperação, a aprendizagem autônoma, aberta, reflexiva, significativa, problematizada portanto, transformadora de sujeitos e realidades.

Enfatizou-se que a EAD é mais do que uma simples metodologia de eliminação de barreiras geográficas e formação de grandes contingentes de trabalhadores, e que esse tipo de educação pode prover mais do que o desenvolvimento 
de competências enunciado no texto da LDB (Gondim e Monken, 2003). Desse modo, a EAD foi apontada como proposta inovadora no modo de ensinar e aprender, que não se restringe à transmissão de conhecimentos, abrangendo a cooperação com o educando no processo de aprendizagem, respeitando sua autonomia em relação a espaço, tempo e ritmo, na busca do fortalecimento de interações sociais. Isso foi muito bem evidenciado no grupo dos dez estudos em que os autores relataram experiências de cursos de formação/qualificação ou projetos em EAD, cujos resultados alcançados foram: formação de comunidades de aprendizagem; instauração de grupalidade entre trabalhadores e professores inseridos no contexto do SUS; fortalecimento dos espaços e processos de gestão e cogestão; e formação de redes de parcerias interinstitucionais para futuros projetos em EPS a distância.

Estudos indicaram que a incorporação da EAD tem contribuído para o fortalecimento do SUS, pois proporciona maior protagonismo dos sujeitos, leva à produção da saúde num senso de coletividade e firma redes de cuidado (Rangel-S et al., 2012; Paulon e Carneiro, 2009).

Alguns autores relataram melhorias nos processos de gestão no âmbito da descentralização, fortalecimento de políticas como a Política Nacional de Humanização e a Política Nacional de Institucionalização em Saúde (Struchiner, Roschke e Riciadi, 2002; Dubeux et al., 2007).

\section{A educação no contexto do século XXI e a formação/qualificação dos profissionais de saúde do SUS}

Nesta seção, apresentam-se a síntese final e um mapa conceitual (Figura 1) construído com base nas principais evidências produzidas pelos estudos e suas implicações para a área da saúde no que se refere à formação/qualificação dos profissionais da saúde mediadas por EAD.

Com o marco da Reforma Sanitária e as transformações no sistema de saúde brasileiro, surgiu a necessidade de se reestruturarem a forma de pensar e o modo de fazer saúde. Os princípios desse processo educativo deveriam levar em conta o conceito ampliado de saúde.

Para alcançar esse objetivo, os processos educativos precisam ajustar-se ao modelo para educação de adultos, de modo permanente, no contexto do trabalho (Oliveira et al., 2013). Além disso, é importante vislumbrar os conhecimentos prévios do educando e suas experiências de vida, para que essa aprendizagem possa produzir significados e ser posta em prática (Ceccim, 2005).

Identifica-se um investimento na formação/qualificação projetadas para a reconstrução da lógica de entendimento no âmbito da saúde, mediante currículos mais abertos e integrados, interdisciplinares, que abordem temas 
relacionados à realidade social, à integralidade das ações e serviços de saúde e à descentralização. Para isso, considera-se a lógica do construtivismo e da educação com as características inerentes ao século XXI, que deve ser contextualizada, globalizada, multidimensional e complexa (Gondim e Monken, 2003; Dubeux et al., 2007; Morin, 2011).

Pois os sujeitos vivem em sociedade, em um conjunto organizado de 'realidades', onde todos que fazem parte dessa sociedade influenciam ou são influenciados em relação a aspectos como a linguagem, o saber, o modo organizado de viver (obrigações, normas). Tanto o sujeito quanto a sociedade são elementos complexos, multidimensionais, em que se consideram os aspectos biológico, psíquico, social e afetivo dos sujeitos, bem como a história, a economia e a cultura como componentes da sociedade (Nunes, Franco e Silva, 2010).

Assim, tendo em vista que a educação necessária para a formação/qualificação dos profissionais de saúde no SUS deve ser multidimensional e complexa, o metaestudo apontou que a EAD pode ser uma proposta inovadora quando amparada nas pedagogias construtivistas, nos pressupostos da educação permanente, na educação de adultos em contexto de trabalho ou no próprio referencial teórico da EAD (quando interacional). Desse modo, a EAD deve ser vista como um modo de fazer educação, e não apenas como uma alternativa para formação/qualificação.

Alguns estudos trabalharam o construtivismo como referencial teórico. Essa perspectiva considera o conhecimento como uma construção humana de significados; o mundo é interpretado pelo educando, as experiências são observadas e compreendidas; o indivíduo se move para intervir na realidade, uma vez que o educando é sujeito ativo do seu próprio conhecimento (Dubeux et al., 2007; Jonassen, 1996). Dentre os representantes considerados clássicos do construtivismo, destacam-se Lev Vigotsky, Jean Piaget, Jonassen e David Ausubel.

Ressalta-se que a aprendizagem significativa ocorre quando um novo conhecimento é ancorado com base em conhecimentos prévios, experiências e vivências no cotidiano (Ausubel, Novak e Hanesian, 1978). Nesse caso, o educando atribui significados aos novos conceitos e tem a real possibilidade de incorporá-los à sua prática. O foco da aprendizagem deve ser o educando, que planeja e se autogoverna no modo de estudar. Essa perspectiva construtivista de aprendizagem leva à reflexão crítica e à ação, à transformação de sujeitos e realidades (Dubeux et al., 2007; Belloni, 2005; Freire, 1996; Carvalho, Muller e Ramos, 2005).

A EAD, quando amparada por ambientes construtivistas de aprendizagem, pode contribuir para que os profissionais de saúde participem de um processo de aprendizagem cujo espaço democrático permite a participação de todos os seus integrantes, com troca de experiências. Essa construção forma o que se chama inteligência coletiva, que nasce no diálogo, no argu- 
mento e na ética (Dubeux et al., 2007; Ceccim, 2005; Nunes, Franco e Silva, 2010; Morin, 2011; Jonassen, 1996; Ausubel, Novak e Hanesian, 1978; Belloni, 2005; Freire, 1996; Carvalho, Muller e Ramos, 2005; Lévy, 2000).

A EAD na perspectiva da EPS envolve a formação de profissionais, e esta visão considera que sujeitos, ações, serviços de saúde, espaços e temas devam ser discutidos, trazendo à luz autoanálise, autogestão, transformação e experimentação (Ceccin, 2005).

A respeito da gestão, o metaestudo evidenciou que comunicação em rede proporcionou uma educação mais democrática no processo de formação dos profissionais e uma gestão compartilhada, no âmbito dos serviços de saúde (Paulon e Carneiro, 2009).

A ideia do modelo de EPS possibilitada por EAD é o da aprendizagem ao longo da trajetória profissional e além dela. O processo de aprendizagem ocorre em uma realidade complexa, em que a comunicação é essencial para a construção coletiva de conhecimentos, troca de experiências e cooperação.

A cooperação é toda relação social em que não ocorre intervenção de qualquer elemento de posição hierárquica superior ou de prestígio; é um processo fomentador de realidades novas, um método de relação sociocultural para o alcance de objetivos comuns e o desenvolvimento de sujeitos mais críticos (Montangero e Maurice-Naville, 1998; Maia et al., 2006).

Esta relação social, sem sobreposição hierárquica, surge quando há superação dos estágios de anomia e heteronomia (egocentrismo) dos sujeitos e quando há elementos que promovam interação/diálogo. Nesse caso, o aprendizado flui para o sentido da integralidade e da prática transformadora (Nunes, Franco e Silva, 2010; Maia et al., 2006).

Entre os elementos passíveis de desencadeamento dos processos dialógicos/interativos, ressalta-se o papel desempenhado pelo tutor e sua potencialidade em proporcionar 'presencialidade' (Laguardia, Casanova e Machado, 2010).

Ressalta-se que o papel do tutor deve considerar o ser humano em sua integralidade, além de contribuir para a aprendizagem do educando. É importante frisar que o professor/tutor é um fomentador da 'inteligência coletiva', não havendo privilégios na interação professor/tutor-aluno; a aprendizagem flui no sentido 'todos-todos' (Lévy, 2000; Barbosa e Rezende, 2006).

Alguns autores acrescentam que um elemento importante para que haja interação é o fórum presente nos ambientes de aprendizagem, pois ele normalmente é um espaço democrático (Nunes, Franco e Silva, 2010; Maia et al., 2006; Laguardia, Casanova e Machado, 2010; Barbosa e Rezende, 2006; Silva, Silva e Santos, 2005).

Entretanto, para o alcance de bons resultados na formação/qualificação de profissionais em saúde, são necessários investimentos na gestão no âmbito da EAD, além do preparo dos docentes. Soma-se a isso a importância de se manterem avaliações constantes dos processos educacionais na educação 
voltada para o trabalho e de se valorizar o trabalho com equipes interdisciplinares (Paim, Alves e Ramos, 2009; Paulon e Carneiro, 2009; Alves e Veloso, 2009; Lima et al., 2004; Brutscher, Sampaio e Pereira, 2012; Candido e Furegato, 2008).

Esta pesquisa apresentou como limitação o fato de ser uma síntese de estudos publicados no Brasil que apresentaram algumas restrições quanto aos aspectos metodológicos. Por este motivo, não foi possível utilizar instrumentos de avaliação de qualidade para seleção dos estudos. Contudo, ressalta-se que a EAD é um tema relativamente novo e que ainda suscita muitas discussões do ponto de vista teórico-conceitual. As pesquisas na área ainda são incipientes no Brasil, com o predomínio de discussões sobre aspectos teóricos ou relatos de experiências em vez de aspectos metodológicos.

Figura 1

Mapa conceitual da síntese gerada com base nas evidências dos estudos

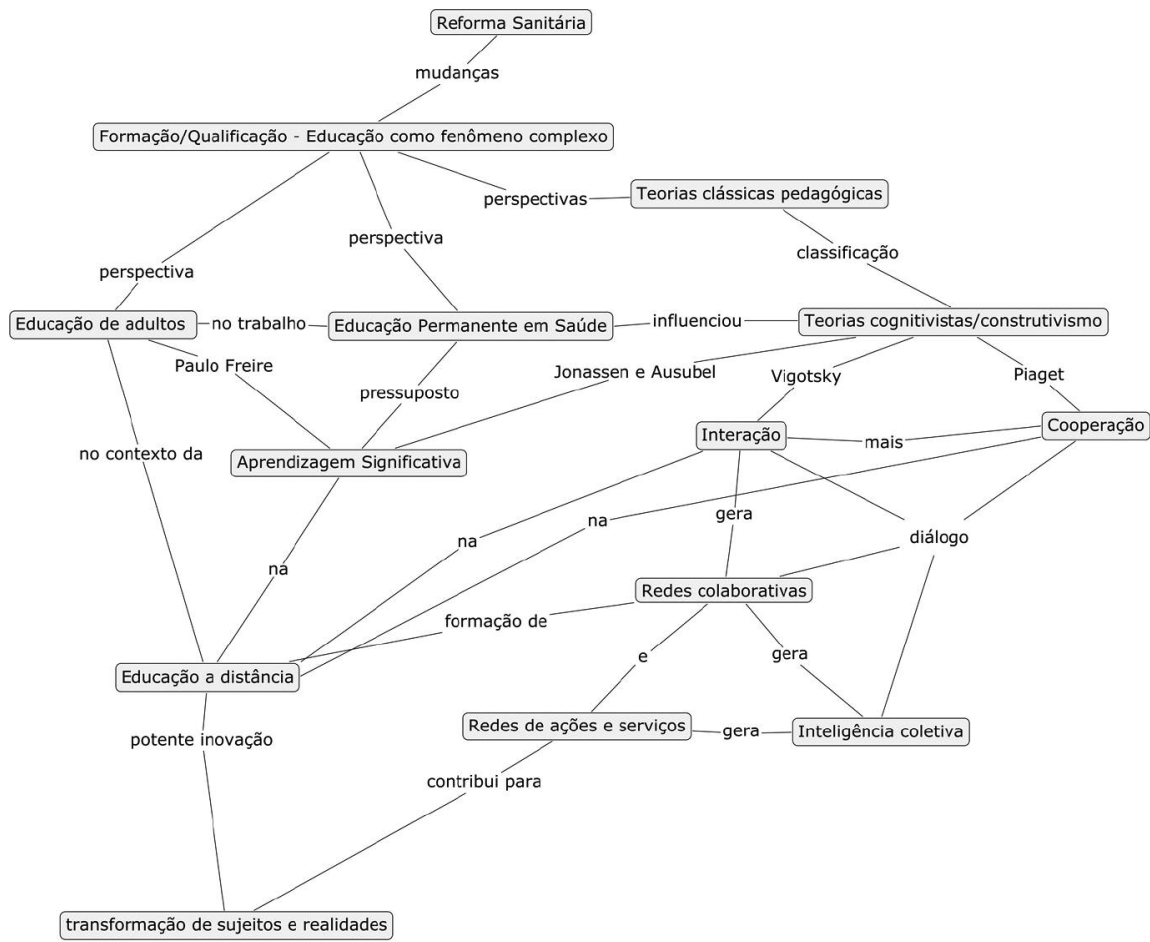

Fonte: As autoras. 


\section{Considerações finais}

Este artigo procurou evidenciar que os estudos envolvendo a formação/qualificação de trabalhadores no contexto do SUS, na modalidade EAD, contemplam aspectos teóricos, de modo diverso, com variações de concepções e práticas. Quanto aos aspectos metodológicos, percebeu-se que os autores trabalharam mais com relatos de experiências do que com estudos qualitativos mais complexos, até pela própria incipiência dos estudos na abordagem qualitativa que tratam o tema no Brasil.

Por isso foi importante o desenvolvimento deste trabalho. Foi possível identificar as principais abordagens conceituais presentes nos estudos e verificar os cursos envolvidos, bem como as demandas de profissionais que têm sido atendidas e elaborar uma síntese destes achados.

A síntese apontou que a utilização da EAD tem sido crescente para formação/qualificação de uma variedade de profissionais, tais como: enfermeiros, gestores, agentes comunitários de saúde, médicos, bem como outros profissionais, em diferentes instâncias no âmbito do SUS.

Os estudos apontaram para uma necessidade de se avançar de uma aprendizagem tradicional para uma aprendizagem construtivista, e que a EAD pode contribuir para este fim. E que a modalidade deve ser considerada não como uma alternativa, mas um novo método para ensinar e aprender, tendo em vista que ela não se restringe a transmissão de conhecimento, eliminação de barreiras geográficas, ou formação de grandes contingentes populacionais.

A proposta da EAD em contextos atuais se respalda em um modo de ensinar e aprender globalizado, multidimensional, considerando que sujeito e sociedade são complexos, logo, no processo ensino-aprendizagem é necessário considerar aspectos biológico, psíquico, social, afetivo, história, economia, cultura, e o modo como o sujeito está inserido na sociedade.

A partir desta reflexão, os estudos apontaram a necessidade de se investir na formação/qualificação de sujeitos para uma nova lógica de entendimento da saúde, mediante currículos mais abertos, interdisciplinares, que reconheçam os princípios do SUS, no que tange à integralidade, à descentralização.

Nos estudos analisados, visualizou-se que quando se investe em um processo ensino-aprendizagem com respaldo em princípios construtivistas - seja na EPS, seja na educação de adultos no âmbito das organizações ou com o referencial próprio da EAD (quando interacional) -, tal modalidade pode viabilizar a formação de redes colaborativas de aprendizagem. E pode ainda fomentar a interação, a cooperação, o estabelecimento de redes de ações e serviços de saúde e de cuidado, assim como o fortalecimento dos espaços de gestão e cogestão e a transformação de sujeitos e suas realidades, de modo a resultar em melhoria dos serviços oferecidos à população. 


\section{Colaboradores}

Francisca Maria de Almeida Vargas contribuiu com a revisão sistemática da literatura, aquisição, tabulação e análise de dados, elaboração, concepção, delineamento do texto, síntese final do metaestudo (metassíntese). Mônica Cristina Nunes da Trindade realizou a revisão sistemática da literatura, aquisição, tabulação e análise dos dados, elaboração do texto. Gisele Damian Antônio cooperou com o delineamento do texto, revisão crítica e síntese final do metaestudo (metassíntese). Mareni Rocha Farias deu sua contribuição no delienamento do texto, revisão crítica e aprovação final para publicação.

Resumen Este estudio buscó caracterizar concepciones teórico-pedagógicas en educación a distancia en la formación/calificación de trabajadores del Sistema Único de Salud e identificar cursos en educación a distancia, amparados en este contexto. La búsqueda sistematizada contempló estudios cualitativos, utilizando los términos: 'educación a distancia' y 'salud'. Se seleccionaron 21 estudios para componer el metaestudio, que consistió en tres etapas: metateoría, metamétodos y metanálisis. En la metateoría, se identificaron cuatro categorías: constructivismo; pedagogía de Paulo Freire; educación permanente en salud; concepciones propias de la educación a distancia. En la etapa metamétodos, se encontraron 11 relatos de experiencia; dos estudios de caso; tres comprendían análisis de contenido; uno comprendía investigación-acción; y el otro, análisis del discurso. En el metanálisis, se identificaron estudios que marcaron: formación de comunidades de aprendizaje; fortalecimiento de espacios de gestión; formación de redes para proyectos en educación permanente. Las discusiones enfatizaron: fortalecimiento del Sistema Único de Salud; protagonismo de los sujetos, formación de redes de cuidados. Se constata que los estudios se restringieron más a los aspectos conceptuales y teóricos que a los metodológicos. Se pusieron en evidencia conceptos amparados en el constructivismo, en la educación permanente en salud, y en referencial teórico propio de la educación a distancia. En los estudios, la educación a distancia fue considerada indispensable para formación/calificación de profesionales en el Sistema Único de Salud.

Palabras clave educación a distancia; Sistema Único de Salud; trabajadores.

\section{Notas}

1 Universidade Federal de Santa Catarina, Programa de Pós-Graduação em Farmácia, Florianópolis, Santa Catarina, Brasil.

$<$ franciscafmdv@gmail.com>

Correspondência: Universidade Federal de Santa Catarina, Farmácia Escola, Campus Universitário, Trindade, CEP 88040-900, Florianópolis, Santa Catarina, Brasil. 
2 Universidade Federal de Santa Catarina, Programa de Pós-Graduação em Assistência Farmacêutica, Florianópolis, Santa Catarina, Brasil.

$<$ monicatrindade25@hotmail.com>

3 Universidade Federal de Santa Catarina, Florianópolis, Santa Catarina, Brasil.

<gdamianantonio@gmail.com>

4 Universidade Federal de Santa Catarina, Programa de Pós-Graduação em Farmácia, Florianópolis, Santa Catarina, Brasil.

$<$ marenif@yahoo.com.br>

\section{Referências}

ALVES, Vânia S.; VELOSO, Rafael. Sistemas de educação a distância: subsídios para a construção do modelo de gestão desta modalidade de ensino no contexto da Secretaria de Saúde do Estado da Bahia. Revista Baiana de Saúde Pública, Salvador, v. 33, n. 1, p. 86-93, 2009.

ANTONIO, Gisele D.; TESSER, Charles D.; MORETTI-PIRES, Rodrigo O. Contribuições das plantas medicinais para o cuidado e a promoção da saúde na atenção primária. Interface: Comunicação, Saúde, Educação, Botucatu, v. 17, n. 46, p. 615-633, set. 2013.

ARETIO, Garcia. Para uma definição de educação a distância. In: LOBO-NETO, Francisco J. S. (org.). Educação a distância: referências e trajetórias. Rio de Janeiro: Associação Brasileira de Tecnologia Educacional; Brasília: Plano Editorial: 2001. p. 21-32.

AUSUBEL, David P.; NOVAK, Joseph D.; HANESIAN, Helen. Educational psychology: a cognitive view. New York: Holt, Rinehart \& Winston, 1978.

BARBOSA, Maria F. S. O.; REZENDE, Flávia. A prática dos tutores em um programa de formação pedagógica a distância: avanços e desafios. Interface: Comunicação, Saúde, Educação, Botucatu, v. 10, n. 20, p. 473-486, dez. 2006.
BELLONI, Maria L. Educação a distância. Campinas: Autores Associados, 1999.

BELLONI, Maria L. Educação a distância e inovação tecnológica. Trabalho, Educação e Saúde, Rio de Janeiro, v. 3, n. 1, p. 187-198, 2005.

BELLONI, Maria L. Educação a distância, mais aprendizagem aberta. In: BELLONI, Maria L. (org.). A formação na sociedade do espetáculo. São Paulo: Loyola, 2002. p. 151-168,

BRASIL. Lei n. 9.394, de 20 de dezembro de 1996. Estabelece as diretrizes e bases da Educação Nacional. Diário Oficial da República Federativa do Brasil, Poder Executivo, Brasília, 23 dez. 1996. Seção 1, p. 27.834 -27.841.

BRASIL. Constituição da República Federativa do Brasil. Brasília: Centro Gráfico do Senado Federal, 1998.

BRASIL. Decreto n. 5.622, de 19 de dezembro de 2005. Regulamenta o artigo 80 da lei n. 9.394, de 20 de dezembro de 1996, que estabelece as diretrizes e bases da educação nacional. Diário Oficial da República Federativa do Brasil, Poder Executivo, Brasília, 20 dez. 2005. Seção 1, p. 1. Disponível em: $<$ www.planalto.gov.br/ccivil_03/_ato20042006/2005/decreto/d5622.htm>. Acesso em: 15 jun. 2016. 
BRASIL. Ministério da Saúde. Portaria n. 1.996, de 20 de agosto de 2007. Dispõe sobre as diretrizes para implementação da Política Nacional de Educação Permanente em Saúde. Diário Oficial da República Federativa do Brasil, Poder Executivo, Brasília, 22 ago. 2007, Seção 1. p. 34.

BRASIL. Ministério da Saúde. Secretaria de Gestão do Trabalho e da Educação na Saúde. Departamento de Gestão da Educação em Saúde. Política Nacional de Educação Permanente em Saúde. Textos Básicos de Saúde, v. 9. Brasília: Ministério da Saúde, 2009a. (Série Pactos pela Saúde 2006, Série B).

BRUTSCHER, Volmir J.; SAMPAIO, Juliana; PEREIRA, Ivoneide L. Potencialidades da educação a distância: modalidades em consolidação. Revista Brasileira de Ciências da Saúde, João Pessoa, v. 16, n. 3, p. 475-480, 2012.

CANDIDO, Mariluci C. F. S.; FUREGATO, Antônia R. F. Transtornos depressivos: um material didático para a educação a distância. Escola Anna Nery Revista de Enfermagem, Rio de Janeiro, v. 12, n. 3, p. 473-478, 2008.

CARVALHO, Fernanda T.; MULLER, Marisa C.; RAMOS, Mauro C. Ensino a distância: uma proposta de ampliação do estudo em bioética. DST - Jornal Brasileiro de Doenças Sexualmente Transmissiveis, Rio de Janeiro, v. 17, n. 3, p. 211-214, 2005.

CASTELlANOS, Marcelo E. P. et al. As provas produzidas por pesquisas qualitativas sobre diabetes tipo 2: uma revisão da literatura. Interface: Comunicação, Saúde, Educação, Botucatu, v. 15, n. 36, p. 257-273, 2011.

CASTELLS, Manuel. A era da informação: economia, sociedade e cultura. v. 3. São Paulo: Paz e Terra, 1999.

CECCIM, Ricardo B. Educação permanente em saúde: desafio ambicioso e necessário. Interface: Comunicação, Saúde, Educação, Botucatu, v. 9, n. 16, p. 161-177, set. 2004/ fev. 2005.
DUBEUX, Luciana S. et al. Formação de avaliadores na modalidade educação a distância: necessidade transformada em realidade. Revista Brasileira de Saúde Materno Infantil, Recife, v. 7, supl. 1, p. 47-52, 2007.

FREIRE, Paulo. Pedagogia da autonomia: saberes necessários à prática educativa. 31. ed. São Paulo: Paz e Terra, 1996.

GARCIA ARETIO, Lorenzo. La educación a distancia: de la teoria a la pratica. Barcelona: Ariel Educación, 2001.

GARCIA, Rosineide M.; BAPTISTA, Rosanita. Educação a distância para qualificação dos profissionais do SUS: perspectivas e desafios. Revista Baiana de Saúde Pública, Salvador, v. 31, supl. 1, p. 70-78, 2007.

GONDIM, Garcia M. M.; MONKEN, Maurício. Saúde, educação, cidadania e participação: desafios para o século XXI - a experiência do Proformar. Trabalho, Educação e Saúde, Rio de Janeiro, v. 1, n. 2, p. 35-39, 2003.

HABERMAS, Jürgen. Teoria de la acción comunicativa. v. 1 e v. 2. Madrid: Taurus, 2001.

JONASSEN, David. O uso das novas tecnologias na educação a distância e aprendizagem construtivista. Em Aberto, Brasília, ano 16, n. 70, p. 70-88, abr./jun. 1996.

LAGUARDIA, Josué; CASANOVA, Angela; MACHADO, Rejane. A experiência de aprendizagem on-line em um curso de qualificação profissional em saúde. Trabalho, Educação e Saúde, Rio de Janeiro, v. 8, n. 1, p. 97-122, mar./jun. 2010.

LANDIM, Cláudia M. M. P. F. Educação a distância: algumas considerações. Rio de Janeiro: Edição da autora, 1997.

LÉVY, Pierre. A inteligência coletiva: por uma antropologia do ciberespaço. 3. ed. São Paulo: Loyola, 2000.

LÉVY, Pierre. O que é o virtual?. São Paulo: Editora 34, 1996. 
LÉVY, Pierre. Cibercultura. São Paulo: Editora $34,1999$.

LIMA, Rita C. D. et al. Formação pedagógica em educação profissional na área de enfermagem: expectativas dos alunos. Revista Enfermagem Uerj, Rio de Janeiro, v. 12, n. 3, p. 356-362, dez. 2004.

LITWIN, Edith (org.). Educação a distância: temas para o debate de uma nova agenda educativa. Porto Alegre: Artmed, 2001.

MAGGIO, Mariana. O tutor na educação a distância. In: LITWIN, E. (org.). Educação a distância: temas para o debate de uma nova agenda educativa. Porto Alegre: Artmed, 2001. p. 93-110.

MAIA, Ivan F. et al. Desenvolvimento da relação de cooperação mediada por computador em ambiente de educação a distância. Interface: Comunicação, Saúde, Educação, Botucatu, v. 10, n. 20, p. 427-441, jul./dez. 2006.

MERHY, Emerson E.; ONOCKO, Rosana (orgs.). Agir em saúde: um desafio para o público. São Paulo: Hucitec, 1997.

MONTANGERO, Jacques; Danielle, MAURICE-NAVILLE. Piaget ou a inteligência em evolução. Porto Alegre: Artmed, 1998.

MOORE, Michael. On a theory of independent study. In: SEWART, David; KEEGAN, Desmond; Holmberg, Borje (eds.) Distance education: international perspectives. London: Croom Helm, 1983. p. 68-94.

MORAN, José M. Contribuições para uma pedagogia da educação on-line. In: SILVA, Marco (org.). Educação on-line: teorias, práticas, legislação e formação corporativa. São Paulo: Loyola, 2003.

MORAN, José M. O que é educação a distância. 2002. Disponível em: <www2.eca.usp.br/ moran/wp-content/uploads/2013/12/dist.pdf $>$. Acesso em: 20 dez. 2005.

MORIN, Edgar. Ciência com consciência. Tradução de Maria D. Alexandre e Maria Alice
Sampaio Dória. 2. ed. Rio de Janeiro: Bertrand Brasil, 1998.

MORIN, Edgar. Introdução ao pensamento complexo. Tradução do francês de Eliane Lisboa. Porto Alegre: Sulina, 2005. 120 p.

MORIN, Edgar. Os sete saberes necessários à educação do futuro. Tradução de Catarina Eleonora F. da Silva e Jeanne Sawaya. Revisão técnica de Edgard de Assis Carvalho. 2. ed. São Paulo: Cortez; Brasília: Unesco, 2011.

NUNES, Tatiana W. N.; FRANCO, Sérgio R. K.; SILVA, Vinícius D. Como a educação a distância pode contribuir para uma prática integral em saúde? Revista Brasileira de Educação Médica, Rio de Janeiro, v. 34, n. 4, p. 554-564, dez. 2010.

OLIVEIRA, Ana E. F. et al. Educação a distância e formação continuada: em busca de progressos para a saúde. Revista Brasileira de Educação Médica, Rio de Janeiro, v. 37, n. 4, p. 578-583, dez. 2013.

PAIM, Marcele C.; ALVES, Vânia S.; RAMOS, Alexandre S. Projeto EAD SUS/BA: incorporação do ensino a distância aos processos de educação permanente para profissionais do Sistema Único de Saúde do estado da Bahia/EAD SUS/BA. Revista Baiana de Saúde Pública, Salvador, v. 33, n. 1, p. 104-112, 2009.

PAIM, Marcele C.; GUIMARÃES, Jane M. M. Importância da formação de docentes em EAD no Processo de Educação Permanente para Trabalhadores do SUS na Bahia. Revista Baiana de Saúde Pública, Salvador, v. 33, n. 1, p. 94-103, 2009.

PARENTE, André (org.). Tramas na rede: novas dimensões filosóficas, estéticas e políticas da comunicação. 2. ed. Porto Alegre: Sulina, 2004.

PATERSON, Barbara L. et al. Meta-study of qualitative health research: a practical guide to meta-analysis and meta-synthesis. Thousand, CA: Sage, 2001.

PAULON, Simone M.; CARNEIRO, Mara L. F. A educação a distância como dispositivo 
de fomento às redes de cuidado em saúde. Interface: Comunicação, Saúde, Educação, Botucatu, v. 13, supl. 1, p. 749-757, 2009.

PRETI, Oreste. Educação a distância e globalização: desafios e tendências. Revista Brasileira de Estudos Pedagógicos, Brasília, v. 79, n. 191, p. 19-30, 1998.

RANGEL-S, Maria L. et al. Redes de aprendizagem colaborativa: contribuição da educação à distância no processo de qualificação de gestores do Sistema Único de Saúde-SUS. Interface: Comunicação, Saúde, Educação, Botucatu, v. 16, n. 41, p. 545-555, abr./jun. 2012.

SILVA, Vilma R.; SILVA, Maria G.; SANTOS, Lidiane B. O. Proposta pedagógica do Profae na perspectiva dos enfermeiros instrutores. Revista Brasileira de Enfermagem, Brasília, v. 58, n. 3, p. 284-289, maio/jun. 2005.
SPADACIO, Cristiane et al. Medicinas alternativas e complementares: uma metassíntese. Cadernos de Saúde Pública, Rio de Janeiro, v. 26, n. 1, p. 7-13, jan. 2010.

STRUCHINER, Miriam; ROSCHKE, Maria A.; RICIADI, Regina M. V. Formação permanente, flexível e a distância pela Internet: Curso de Gestão Descentralizada de Recursos Humanos em Saúde. Revista Panamericana de Salud Publica, Washington, v. 11, n. 3, p. 158-165, 2002.

TORRES, Milta N. F. B. Educação a distância e a formação em saúde: nem tanto, nem tão pouco. Trabalho, Educação e Saúde, Rio de Janeiro, v. 3, n. 1, p. 171-186, mar. 2005.

Recebido em 25/06/2014

Aprovado em 16/12/2014 